\title{
Thinking on Construction of Feature Literature in College Libraries of Minority Areas
}

\author{
Hu Chen \\ Library \\ XiZang Agriculture and Animal Husbandry College \\ Linzhi, China
}

\begin{abstract}
The construction of feature in college libraries of minority areas has significance on integral development of the areas. According to situation of main college libraries of Tibet Autonomous Region, significance and principles, problems in construction of characteristic collection in colleges of minority areas, and countermeasures are proposed.
\end{abstract}

Keywords-minority areas; colleges; characteristic collection; problems; countermeasures

\section{INTRODUCTION}

Feature literature of nationalities means nationalities record their development history through characteristic ways and hand it down from generation to generation. Feature covers local culture, economics, religion, art, geography and history. The construction of feature in college libraries of minority areas makes people know more about the development of these areas and makes the formulation of development policies more easily. Therefore, development and utilization of feature have significance on coordinated development of nationalities.

\section{SigNIFICANCE ON CONSTRUCTION OF FEATURE IN COLLEGE LIBRARIES OF MINORITY AREAS}

\section{A. Effectively Accumulate and Preserve Related Data Including Historical Data in Minority Areas}

Preserving ethnic literature is effective way to record development history of nationalities. People know vicissitude of nationalities through searching literature, which provides powerful basis for the development and the behavior of later generations. Ethnic literature not only records humanity and folk custom of areas but also record detailed information of the areas, including geographical environment, climate, religion and history. Ethnic literature with round and detailed records can effectively preserve related data and development history of areas. After long-term documentation, ethnic literature can accumulate data of related nationalities and record the historical development of ethnic groups.

\section{B. Provide Effective Information for the Career Development in Minority Areas}

The contents of ethnic literature cover information of aspects in an area in all ages, including politics, information, culture, art and religion of this nationality, as well as mountains and rivers, landscapes, resources and products of the area. The long time span and the wide aspects of records make ethnic literature cover all valuable information related to the development of an area. The construction of feature in college libraries of minority areas is increasingly sound. The scope of records is increasingly large and the objects recorded are increasingly affluent. It provides more and more detailed historical basis for the development of the area and makes people more easily find the rules of economic development and cultural progress of the area. Meanwhile, it provides historical records for decision makers so that they can pertinently formulate efficient policies, in order to develop careers of minority areas and assist the civilization construction of socialism.

\section{Provide Help for the Function of Literature Resources in Our Country}

The construction of feature in college libraries of minority areas improves data record and literature preservation of minority areas. At the meantime, it popularizes among college students and educates them, laying solid foundation for the long-term development of ethnic literature. The contents of ethnic literature cover historical records of nationalities and areas except for the Han nationality. Improving the construction of literature of minority areas has distinctly important significance on the integrity of overall literature system in our country. The exertion of functions such as recording and providing basis of literature system also depends on integrity of the system. Therefore, the construction of literature in college libraries of minority areas avails the exertion of functions of literature resources in our country.

\section{PRINCIPLES FOR CONSTRUCTION OF FEATURE IN COLLEGE LIBRARIES OF MINORITY AREAS}

\section{A. Principle of Adjusting Measures to Local Conditions}

Our country has research-based universities and teachingbased universities. Majority of universities are regional. The construction of literature in college libraries must conform to the orientation of universities, promote local cultural and economic development and advocate ethnic characteristics, in order to serve the construction of cultural undertakings and train excellent talents. For example, Tibet University makes use of language advantage because it's located in Tibet, 
cooperate with related units and institutions and construct databases with ethnic characteristics, such as Tibetology ebook database, China Tibet National Knowledge Infrastructure (Tibetan edition of China National Knowledge Infrastructure) and bidirectional machine translation system of Chinese and Tibetan. Meanwhile, because it is located in Lasa, the cultural center of Tibet, numerous Tibetan classics, especially Tibetan ancient books are collected. Tibet University plays an important role in popularizing Tibetan culture and training excellent talents through combining library construction with teaching research. Tibetan Traditional Medical College collects tremendous literature and ancient books related to Tibetan medicine, having made great contributions to the cultivation of talents related to Tibetan medicine.

\section{B. Principle of Pertinence and Coherence}

The construction of literature system in college libraries of minority areas must have explicit pertinence and follow the principle of coherence. The pertinence refers to the purpose of college library construction and the service object of library. For colleges, library construction must serve teaching and scientific research. Therefore, the college library construction in minority areas should emphasize teaching and scientific research, popularize local culture and develop regional economy to train excellent talents. Coherence means the literature construction in libraries of minority areas is lasting, requiring long-term literature accumulation and work plan. Therefore, colleges in minority areas should formulate scientific development plan according to culture, economics and social situation of local areas, plan detailed job aim and construct sound library literature system.

\section{Principle of Practicality}

The construction of literature in college libraries of minority areas should be practical to get long-term development. Therefore, in the construction of library, colleges in minority areas should combine with development goals of schools and local areas to serve them. The construction of college libraries can only play a role in local economic and social development. For example, the library of Tibetan Traditional Medical College has been devoted to collecting cultural ancient books related to Tibetan medicine for a long time. The chief librarian of this library, Landon Dorji Dolkar, presides over the compilation of 1-54 volumes of inventory and 2 volumes of abbreviation catalog including Kangyur focusing on Tibetan medicine, Tengyur, traditional Tibetan medicine and mathematical astronomy, and collections of celebrities. It is the most comprehensive and most authoritative reference book that reflects Tibetan ancient books. It ends the history that there is no catalog set of Tibetan documents related to traditional Tibetan medicine and mathematical astronomy. She achieved with glory of 2013 "China Library Model". Therefore, in library construction, colleges of minority areas must closely combine with local human development to guarantee long-term development of feature construction in minority areas.

\section{PRoblems in CONSTRUCTING FeAture OF COLLEGE LIBRARIES IN MINORITY AREAS}

\section{A. College Libraries in Minority Areas Fail to Realize the Importance of Feature Construction}

Insufficient attentions are paid to local literature of minority areas, so the construction progress of feature in libraries is slow. Libraries cannot attach importance to the construction of literature with ethnic characteristics. And some literature has too small opening degree. At present, a few colleges at home attach great importance to the construction of literature with ethnic characteristics. Besides, they carefully preserve document literature and seldom provide it for people to refer to or show them. For example, teaching Thang-ga is the characteristic library collection resource of Tibetan Traditional Medical College. Because the digitization of it is difficult and it belongs to cultural relic, it is only open to the students in teaching. It isn't shown to the public at ordinary times. If the problem of preservation of cultural relics can be solved and it is open to the public, it will tremendously publicize the area.

\section{B. College Libraries in Minority Areas Have Poor Performance in Collecting and Preserving Feature}

Feature refers to paper data that record historical development, landscapes and history of minority areas and have limited stock, so it's more precious. Restricted by technical conditions and facilities, colleges fail to carefully protect and repair literature that people can borrow. The protection of literature cannot put into practice. Besides, deficiencies exist in data collection. At present, few colleges establish the post to maintain and collect ethnic data in libraries. Data depend on social donation or government distribution. Tremendous document literature scatter among the people; local government agencies seldom explicitly record the location of literature and they depend on collection place to actively report and register. Therefore, collection and maintenance of feature in college libraries fail to provide efficient and high quality literature information for economic and social development of minority areas.

\section{The Construction of Professional Team in College Libraries of Minority Areas Is Unsound.}

College libraries in minority areas lack professional talents in management. It's the current situation of college libraries in minority areas and obstructs the construction of all domestic college libraries. In most cases, libraries provide official posts with very little to do in talent transfer. People can become library administrators through simple training, failing to professionally manage ethnic literature. Besides, the theoretical research of colleges on management of local ethnic literature collected in libraries is basic and completely cannot meet the demands in preservation and inheritance of precious literature. Librarians lack skills to save endangered literature, causing the loss of precious records. The library with inadequate reserve of talents directly leads to few features with low quality in minority areas. 


\section{College Libraries in Minority Areas Fail to Fully Develop Feature}

College libraries take local ethnic literature as characteristic collection and collect a certain amount of local characteristic collection. However, college libraries fail to fully develop the existing ethnic literature because the record of ethnic information is different and diversified, the library workload doesn't match with librarians. For example, the ethnic information recorded by ethic minorities in ethnic characters or other habitual ways is difficult for people to translate after long-term development and the evolution of ethnic characters, so college libraries fail to fully develop literature and cannot make use of its value.

\section{E. College Libraries in Minority Areas Fail to Effectively Publicize Feature}

Attentions from the pubic aren't paid to the construction of literature with ethnic characteristics in college libraries. Only librarians of colleges know about it. Insufficient attentions make the construction of literature with ethnic characteristics in college libraries cannot get social support from local areas, leading to the neglect of related government sectors. Because college libraries have limited social influence and inadequate propaganda, local people cannot understand the work in college libraries.

\section{STRATEGIES TO OPTIMIZE THE CONSTRUCTION OF FEATURE IN COLLEGE LIBRARIES OF MINORITY AREAS}

\section{A. Deepen the Understanding and Strengthen the Construction of Literature Resources in College Libraries of Minority Areas}

In order to construct feature in college libraries of minority areas, first, we should attract the attention of related departments and local people, improve their consciousness in construction of feature in libraries and enhance propaganda, as well as put characteristic collection in the first place. Second, bring in advanced and scientific management methods and measures that adapt to the development of times, in order to thoroughly exert the functions of characteristic resources. Third, colleges should strengthen the exchange and cooperation with local ethnic management center to exchange resources; in library construction, colleges should combine with local culture and ethnic characteristics and attach importance to the construction of characteristic collections. Finally, formulate detailed long-term development plan, increase input and purchase books with ethnic characteristics according to the development plan to increase the proportion of ethnic literature.

\section{B. Establish Scientific Methods to Manage Feature Resources}

Management mechanism of college libraries is applicable to the development of libraries and is formulated according to college orientation. After introducing characteristic ethnic literature, colleges should establish collection place and management methods for feature. Professional and pertinent management methods are provided to manage characteristic ethnic literature. College libraries must furthest preserve feature and develop its value when guaranteeing the opening degree. They must avoid the value of feature is neglected in development and management of general literature. Furthermore, only professional management methods can furthest develop characteristic ethnic literature, better serve local economic, social and cultural development and help ethnic minorities to preserve historical literature.

\section{Strengthen the Construction of Talent Team for Feature Resources in College Libraries of Minority Areas}

Most of administrators in college libraries don't attend professional training. They depend on years of experience and some common sense in the management of general literature. However, in the management and development of characteristic ethnic literature with special requirements, nonprofessional work team cannot guarantee work efficiency, and even cause the loss of data and the destruction of literature because of improper operation and nonprofessional management. Therefore, college libraries must bring in professional talents of book management and train professional, efficient and high-level team to manage characteristic ethnic literature, in order to realize sustainable and comprehensive development. At present, college libraries in Tibet don't have professional talents of library science and information science, greatly influencing the construction and development of libraries in Tibet.

\section{Implement Digitization Construction of Feature Resources}

Characteristic ethnic literature records extensive contents and has long history, and most of them use recording mode with ethnic characteristics. Besides, paper-based literature has limited preservation time and is more easily to abrade and lose. The subjective and objective factors make the contents of ethnic literature more precious, and have higher requirements for development and preservation of literature. Some literature even becomes the unique copy. According to the physical truth that the characteristic ethnic literature is precious and the quantity of borrowing in college libraries is large, libraries should strengthen the digitization construction of literature resources, timely record precious information and expand the circulation scope of them and develop potential audiences of characteristic ethnic data. For example, the library of Tibetan Traditional Medical College mentioned above has implemented digitization of Tibetan ancient books, but the progress is slow because of the deficiency of librarians and talents.

\section{E. Implement Cooperation between Libraries to Share Feature Resources}

In construction of characteristic collection, college libraries must exchange and cooperate with local libraries and contact with local ethnic management center, in order to share precious ethnic resources and seek the joint development of libraries and local people. The construction of college libraries has limited funds. They must cooperate with libraries in local areas at all levels in protection technology, development technology and recovery technology to jointly establish complete and comprehensive management system of 
characteristic data and realize collaborative management of characteristic resources in different libraries.

\section{F. Publicize Collection and Utilization of Local Feature Resources in College Libraries of Minority Areas}

Characteristic ethnic collection in colleges of minority areas has limited social influence and acceptance because the public fail to thoroughly understand it. College libraries should publicize characteristic collection and show characteristics. Meanwhile, they can refer to successful experience of other colleges in propaganda way, such as invite celebrities in all sectors of society to give lectures and carry out academic exchange, in order to attract attentions of the public and publicize characteristic collections in libraries.

\section{CONCLUSION}

In conclusion, the construction of feature in college libraries of minority areas can provide help for local economic, social, cultural, religious and artistic development. At the meantime, the construction of characteristic collections in college libraries needs explicit principles and orientation and applies scientific strategies.

\section{REFERENCES}

[1] Wang Yue. Discussion on Integration of Information Resources of Classical Literature in College Libraries of Tibet [J], Management Observer, 2017, (03): 99-101

[2] Feng Jing. Analysis on Ways of Cultural Construction of College Libraries in Minority Areas--Take Xinjiang as an Example [J], Xinjiang Social Science Forum, 2016, (03): 110-112

[3] Jin Honghua. Analysis on Current Situation in Constructing Feature Resource Library of College Libraries in Minority Areas [J], Science and Technology Vision, 2015, (02): 227

[4] Qu Guanjun, Yi Zhiliang. Research on Problems in Cultural Inheritance and Development of College Libraries of Minority Areas--Take Cultural Construction of Library in North Minzu University as an Example [J], Heilongjiang Science and Technology Information, 2012, (32): 155

[5] Ge Rile. Thinking on Construction of Libraries in Colleges of Minority Areas--Take Library of Chifeng University as an Example [J], Journal of University (Natural Science Edition), 2012, (08): 149-150 